\title{
KECANDUAN GAME ONLINE DENGAN INSOMNIA PADA REMAJA
}

\author{
Fraldy Robert Mais ${ }^{1}$, Sefti S. J. Rompas ${ }^{2}$, Lenny Gannika ${ }^{3}$ \\ ${ }^{1}$ Mahasiswa Program Studi Ilmu Keperawatan Fakultas Kedokteran Universitas Sam \\ Ratulangi \\ 2,3Program Studi Ilmu Keperawatan Fakultas Kedokteran Universitas Sam Ratulangi \\ Email : fraldy.mais@gmail.com
}

\begin{abstract}
Online games are a means of entertainment that is often used by Adolescents. Excessive use of this online game can make the users become addicted to online games. Adolescents who are addicted to playing online games will use their time to play, and forgot other activities like taking a rest and sleeping. it can make them experience insomnia sleep disorders. The purpose of this research is to find out the relationship between online game addiction with insomnia in adolescent in Senior High School 1 Tondano. This research used descriptive analytic with Cross Sectional Study approach. The sampling technique used purposive sampling, with a total sample of 68 adolescents. The results of statistical test studies using Spearman test at a significance level of 95\% or $\alpha=0.05$, obtained a significant value, $r$ $=0.003<\alpha=0.05$. Conclusion there is a significant relationship between online game addiction with insomnia in adolescents. Suggestions are expected for schools and parents to supervise teenagers in playing online games, and for teens to improve their self-control in playing online games and pay attention to time to rest and sleep.
\end{abstract}

Key Words : Online Game Addiction, Insomnia, Adolescent

\begin{abstract}
Abstrak: Game online merupakan suatu sarana hiburan yang sering digunakan oleh para remaja. Penggunaan yang berlebihan terhadap game online ini dapat menyebabkan para penggunanya mengalami kecanduan game online. Remaja yang mengalami kecanduan dalam bermain game online akan menggunakan waktunya untuk bermain, sehingga mereka melupakan aktivitas istirahat dan tidur. hal tersebut dapat membuat mereka mengalami gangguan tidur insomnia. Tujuan untuk mengetahui hubungan antara Kecanduan game online dengan insomnia pada remaja di SMA N 1 Tondano. Desain Penelitian yang digunakan yaitu Deskriptif Analitik dengan pendekatan Cross Sectional Study. Teknik pengambilan sampel menggunakan Purposive Sampling, dengan jumlah sampel sebanyak 68 remaja. Hasil Penelitian uji statistik menggunakan uji Spearman pada tingkat kepercayaan $95 \%$ atau $\alpha=0,05$, didapatkan nilai $r=0,003<\alpha=0,05$. Kesimpulan terdapat hubungan yang signifikan antara kecanduan game online dengan insomnia pada remaja. Saran diharapkan bagi pihak sekolah dan orang tua untuk mengawasi para remaja dalam bermain game online, dan untuk remaja agar supaya dapat meningkatkan kontrol diri dalam bermain game online serta memperhatikan waktu untuk istirahat dan tidur.
\end{abstract}

Kata Kunci : Kecanduan Game online Insomnia, Remaja 


\section{PENDAHULUAN}

Perkembangan teknologi dan informasi yang semakin pesat memberikan kemudahan dan manfaat bagi masyarakat di era modern ini. Salah satu perkembangan teknologi yang semakin pesat adalah penggunaan internet yang saat ini sudah sangat mudah untuk diakses dari berbagai macam tempat. Perkembangan internet ini memberikan kemudahan kepada penggunaanya untuk memperoleh informasi baik dalam negeri maupun luar negeri. Penggunaan internet tersebut tidak hanya memiliki fitur untuk mencari informasi, tetapi juga untuk berkomunikasi antar sesama pengguna tanpa harus bertemu secara langsung, bahkan saat ini internet memiliki fitur untuk hiburan yaitu, Game online (Astuti, 2018).

Berdasarkan hasil survey yang dilakukan oleh Asosiasi Penyelenggara Jasa Internet di Indonesia (APJII) tahun 2018, jumlah pengguna internet di Indonesia menunjukan angka 171,17 juta jiwa dari total populasi penduduk Indonesia 264,16 juta jiwa, dan disulawesi utara sendiri jumlah populasi yang menggunakan internet sebanyak $70 \%$ dari total populasi. Pengguna internet tertinggi berdasarkan usia 15-19 tahun sebesar 91\%, perangkat yang digunakan untuk mengakses internet adalah 93,9\% terhubung ke internet melalui smartphone/tablet, dan $54,13 \%$ pengguna internet di Indonesia memanfaatkan internet sebagai hiburan yaitu untuk bermain game Online (APJII, 2018).

Game online adalah permainan digital yang bisa dimainkan ketika perangkat yang digunakan terhubung ke jaringan internet sehingga memungkinkan penggunanya untuk dapat saling terhubung bermain bersama-sama dengan pemainpemain lain yang mengakses game tersebut diwaktu yang bersamaan walaupun ditempat yang berbeda tanpa harus bertemu secara langsung (Young, 2009).

Data pengguna game online yang tarbaru dikeluarkan oleh Newzoo (Global
Games Market Report) pada tahun 2018, menunjukan bahwa jumlah pengguna game online di dunia sebanyak 2,3 miliar, kemudian pengguna game online $\mathrm{di}$ kawasan Asia Pasifik berjumlah 1,2 miliar atau $50 \%$ dari total populasi pengguna game online di dunia, dan di Indonesia sendiri jumlah pengguna game online mencapai 82 juta jiwa, bahkan Indonesia saat ini menempati peringkat ke 17 didunia dengan pendapatan melalui game online. Menurut Gentille, Lynch, Linder dan Walsh (2004) bermain game online dapat memberikan dampak negatif kepada pengguna-pengguna game online tersebut. Beberapa dampak negatif yang ditimbulkan dari game online antara lain adalah membuat penggunannya kecanduan dalam bermain game online karena sistem level dalam game online yang membuat para penggunanya secara terus menerus bermain demi mencapai level yang lebih tinggi, tanpa disadari hal tersebut membuat penggunanya mengalami kecanduan game online.

Kecanduan game online merupakan suatu sikap yang berlebihan dalam bermain game online dimana para penggunanya akan terus menerus bermain dan sulit untuk berhenti (Nurdilla, 2018). World Health Organisation (WHO) saat ini sudah resmi menyatakan bahwa kecanduan game online sebagai penyakit gangguan mental untuk pertama kalinya dalam $11^{\text {th }}$ Revision of the International Classification of Diseases (ICD-11). Penyakit kecanduan game online ini memiliki beberapa karakteristik antara lain pola perilaku bermain secara terus-menerus yang ditandai dengan gangguan kontrol terhadap game, sehingga game lebih diutamakan dari pada kebutuhan hidup lainnya (WHO, 2018). Menurut hasil penelitian yang dilakukan oleh Koo, Wati, Choong, \& Hea (2011) di Korea selatan ditemukan data dari 384 responden sebanyak $73,4 \%$ mengalami kecanduan game online dan dari 706 responden siswa sebanyak 83,6\% mengalami kecanduan game online. Ada juga penelitian yang dilakukan oleh Rondo 
(2019) di salah satu sekolah di Sulawesi utara, ditemukan data gambaran kecanduan game online bahwa dari 78 responden siswa terdapat 60 responden yang mengalami kecanduan game online tidak terkontrol.

Kecanduan game online lebih sering terjadi pada remaja, karena remaja dianggap lebih rentan terhadap kecanduan game online dari pada orang yang sudah dewasa. Hal tersebut dikarenakan remaja lebih suka untuk mencoba hal-hal yang baru untuk memperoleh kesenangan secara pribadi. Kecanduan game online memiliki konsekoensi yang sangat besar karena remaja biasanya akan melupakan aktivitas yang lain salah satunya adalah istirahat dan tidur (Young, 2009). Menurut Lam (2014), kecanduan game online memiliki beberapa resiko yang besar, yaitu dapat menyebabkan gangguan/masalah tidur termasuk diantaranya adalah insomnia.

Insomnia merupakan suatu kondisi dimana seseorang mengalami kesulitan untuk tidur atau gangguan saat tidur, sehingga dapat mempengaruhi aktivitasnya. Salah satu faktor penyebab terjadinya insomnia adalah gaya hidup diantaranya adalah penggunaan game online yang berlebihan atau terus menerus (Owens, 2014). Berdasarkan hasil penelitian yang dilakukan oleh Lam (2014), ditemukan bahwa remaja yang kecanduan bermain game online akan mengalami kualitas tidur yang buruk serta durasi tidur yang pendek, hal tersebut akan membuat remaja yang kecanduan game online akan mengalami insomnia. Hal tersebut didukung oleh hasil penelitian yang dilakukan oleh Nurdilla (2018), bahwa remaja yang kecanduan game online cenderung akan terus menambah waktunya untuk bermain game online dan melupakan waktu untuk beristirahat dan tidur, hal tersebut dapat menyebabkan remaja mengalami insomnia.

Studi pendahuluan yang dilakukan peneliti pada tanggal 19 Februari 2020 di SMA Negeri 1 Tondano melalui wawancara dengan pihak sekolah dan siswa. Data yang diperoleh dari bagian tata usaha, jumlah siswa keseluruhan di SMA N 1 Tondano adalah 848 siswa. Untuk jumlah siswa kelas $\mathrm{X}$ berjumlah 327 siswa dan jumlah siswa kelas XI berjumlah 273 siswa dengan total jumlah siswa kelas $\mathrm{X}$ dan kelas XI berjumlah 600 siswa. Berdasarkan data yang diperoleh peneliti di SMA N 1 Tondano, jumlah siswa kelas $\mathrm{X}$ dan XI yang aktif menggunakan game online berjumlah 178 siswa. Guru bimbingan konseling (BK) SMA N 1 Tondano mengatakan, rata-rata siswa yang datang terlambat kesekolah kurang lebih 30 siswa setiap harinya, dimana alasan keterlambatan siswa tersebut sebagian besar terlambat karena terlambat bangun akibat tidur larut malam dan sisanya terlambat dengan alasan tempat tinggal yang jauh. Peneliti juga melakukan wawancara dengan dua orang guru pengajar matematika dan fisika, mengatakan bahwa mereka sering menghukum siswa yang kedapatan bermain game online saat proses belajar mengajar berlangsung. Hasil wawancara dengan 10 siswa di SMA N 1 Tondano, ditemukan bahwa 8 siswa sering tidur larut malam karena susah tidur akibat bermain game online, mereka mengatakan bahwa ketika sedang bermain game online mereka akan terus-menerus memainkan game online tersebut sampai permainan itu selesai, apalagi saat bermain dengan temantemannya dalam game online tersebut. Tanpa disadari mereka sudah ketagihan untuk terus memainkan game online, sehingga menyebabkan kecanduan dalam bermain, akibat dari bermain game online itulah yang membuat mereka mengalami gangguan/masalah tidur. Berdasarkan fenomena tersebut, peneliti tertarik untuk melakukan penelitian dengan judul "Hubungan kecanduan game online dengan Insomnia pada remaja di SMA N 1 Tondano".

\section{METODE PENELITIAN}

Jenis penelitian yang digunakan adalah penelitian kuantitatif dengan 
pendekatan cross sectional. Penelitian ini dilaksanakan secara online pada siswasiswi SMA N 1 Tondano pada bulan April 2020. Populasi dalam penelitian ini adalah seluruh siswa-siswi yang bermain game online di SMA N 1 Tondano dengan jumlah 178. Teknik sampling yang digunakan dalam penelitian ini adalah purposive sampling. Jumlah sampel yang didapatkan dalam penelitian ini sebanyak 68 sampel yang telah memenuhi kriteria inklusi dan eksklusi. Instrumen penelitian yang digunakan untuk mengukur variabel kecanduan game online menggunakan kuesioner yang sudah pernah digunakan oleh Fransiska (2015), kuesioner ini terdiri dari 40 item pertanyaan dalam bentuk skala likert dengan parameter penilaian skor 1120 dikategorikan kecanduan game online terkontrol dan skor 121-240 dikategorikan kecanduan game online tidak terkontrol. Instrumen penelitian yang digunakan untuk mengukur variabel insomnia menggunakan kuesioner Insomnia rating scale yang terdiri dari 11 item pertanyaan dengan parameter peniliaian skor 11-19 dikategorikan tidak ada keluhan insomnia, skor 20-27 dikategorikan Insomnia ringan, skor 28-36 dikategorikan insomnia berat, skor 37-44 dikategorikan insomnia sangat berat.

Pengolahan data yang diperoleh dari hasil penelitian ini diolah secara manual dan dianalisis secara statistik melalui komuterisasi dengan beberapa tahap yaitu selecting, editing, coding, cleaning, tabulating dan entry (Notoadmodjo, 2012). Analisa Univariat pada penelitian ini akan menghasilkan distribusi frekuensi yang memberi gambaran mengenai jumlah dan presentase dari variabel kecanduan game online dan variabel insomnia. Analisa bivariat adalah analisis yang dilakukan terhadap dua variabel yang diduga saling berhubungan atau berkolerasi (Notoatmodjo, 2012). Analisa bivariat dalam penelitian ini yaitu untuk menguji hubungan kecanduan game online dengan insomnia pada remaja di SMA N 1 Tondano. Uji statistik yang digunakan adalah uji Fisher's Exact Test dengan nilai $\alpha=0,05$. Bila nilai $\mathrm{p} \leq$ nilai $\alpha$, maka keputusannya adalah Ho ditolak dan $\mathrm{Ha}$ diterima.

\section{HASIL dan PEMBAHASAN}

\section{A. HASIL}

1. Karakteristik Responden

Tabel 1. Distribusi Frekuensi Responden Berdasarkan Jenis Kelamin

\begin{tabular}{ccc}
\hline Jenis Kelamin & n & \% \\
\hline Laki-laki & 46 & 67,6 \\
Perempuan & 22 & 32,4 \\
\hline Total & $\mathbf{6 8}$ & $\mathbf{1 0 0}$
\end{tabular}

Sumber : Data Primer, 2020

Berdasarkan hasil penelitian pada 68 responden, ditemukan bahwa mayoritas responden berjenis kelamin laki-laki yaitu sebanyak 46 orang $(67,6 \%)$.

Tabel 2. Distribusi Frekuensi Responden Berdasarkan Usia

\begin{tabular}{ccc}
\hline Usia & n & \% \\
\hline 15 tahun & 13 & 19,1 \\
16 tahun & 46 & 67,6 \\
17 tahun & 9 & 13,2 \\
\hline Total & $\mathbf{6 8}$ & $\mathbf{1 0 0 , 0}$
\end{tabular}

Sumber : Data Primer, 2020

Berdasarkan hasil penelitian pada 68 responden, ditemukan bahwa semua responden berada dalam rentang usia 15-17 tahun, dimana sebagian besar responden berusia 16 tahun yaitu sebanyak 46 responden $(67,6 \%)$.

Tabel 3. Distribusi Frekuensi Responden Kecanduan Game Online

\begin{tabular}{ccc}
\hline $\begin{array}{c}\text { Kecanduan Game } \\
\text { Online }\end{array}$ & n & \% \\
\hline Terkontrol & 19 & 27,9 \\
Tidak Terkontrol & 49 & 72,1 \\
\hline Total & $\mathbf{6 8}$ & $\mathbf{1 0 0 , 0}$ \\
\hline Sumber : Data Primer, 2020 & &
\end{tabular}

Hasil penelitian menunjukan bahwa sebagian besar responden mengalami kecanduan game online tidak terkontrol yaitu sebanyak $49(72,1 \%)$ dan lainnya 
mengalami kecanduan game online terkontrol yaitu sebanyak $19(27,9$

Tabel 4. Distribusi Frekuensi Insomnia

\begin{tabular}{ccc}
\hline Insomnia & $\mathbf{n}$ & $\mathbf{\%}$ \\
\hline Ringan & 51 & 75 \\
Berat & 17 & 25 \\
\hline Total & $\mathbf{6 8}$ & $\mathbf{1 0 0 , 0}$ \\
\hline Sumber : Data Primer, 2020 & &
\end{tabular}

Hasil penelitian menunjukan bahwa dari 68 responden, yang mengalami insomnia ringan sebanyak $51(75 \%)$, dan yang mengalami insomnia berat sebanyak $17(25 \%)$.

\section{Hubungan kecanduan Game Online dengan kejadian Insomnia}

Tabel 5. Hubungan Kecanduan Game Online Dengan Insomnia Pada Remaja Di SMA N 1 Tondano

\begin{tabular}{cccc}
\hline & \multicolumn{1}{c}{$\begin{array}{c}\text { Kecanduan } \\
\text { Game } \\
\text { Online }\end{array}$} & Insomnia \\
\hline \multirow{2}{*}{$\begin{array}{c}\text { Kecandua } \\
\text { n Game } \\
\text { Online }\end{array}$} & $\begin{array}{c}\text { Correlation } \\
\text { Coefficient }\end{array}$ & 1.000 & $0.360^{* *}$ \\
\cline { 2 - 4 } & $\begin{array}{c}\text { Sig. (2- } \\
\text { tailed) }\end{array}$ & 0.003 \\
\cline { 2 - 4 } Insomnia & $\begin{array}{c}\mathrm{N} \\
\text { Correlation } \\
\text { Coefficient }\end{array}$ & $0.360^{* *}$ & 68 \\
\cline { 2 - 4 } & $\begin{array}{c}\text { Sig. (2- } \\
\text { tailed) }\end{array}$ & 0.003 & \\
\cline { 2 - 4 } & $\mathrm{N}$ & 68 & 68 \\
\hline
\end{tabular}

Sumber : Data Primer, 2020

Hasil penelitian menggunakan uji korelasi Spearman dengan tingkat kepercayaan $95 \%$ didapatkan nilai $r=0,003<\alpha=0,05$. Hasil tersebut menunjukan bahwa hipotesis peneliti diterima yang artinya, ada hubungan yang signifikan antara kecanduan game online dengan insomnia pada remaja di SMA N 1 Tondano.

\section{PEMBAHASAN}

Berdasarkan tabel 1 dan 2 menunjukkan laki-laki cenderung lebih tertarik untuk bermain game online dibandingkan dengan perempuan. Menurut peneliti salah satu hal yang menyebabkan laki-laki lebih sering menggunakan game online adalah sifat bawaan yang dimiliki oleh remaja laki-laki, dimana mereka lebih tertarik terhadap petualangan dan aksi dibandingkan dengan perempuan yang lebih tertarik dengan suasana yang damai dan aman. Menurut Jiang (2014), Laki-laki lebih cenderung menunjukan tingkat keterhubungan mereka dengan internet khususnya penggunaan game online yang lebih tinggi dari pada perempuan, hal ini dikarenakan laki-laki sering kali merasa bahwa game online merupakan hiburan yang membuat mereka bahagia dengan tantangan-tantangan yang ada di game online.

Berdasarkan usia, Remaja yang cenderung melakukan aktivitas bermain game online adalah remaja yang berada dalam rentang usia 15-17 tahun. Menurut Young (2009), pada usia tersebut remaja berada pada masa yang rentan, dimana mereka lebih senang melakukan aktivitas yang dapat memberi mereka kesenangan secara pribadi. Menurut Kuss dan Griffith (2012), pada usia 15-17 tahun, rasa tertarik remaja dalam bermain game online secara umum akan berkembang, dimana mereka lebih suka menghabiskan waktu untuk bermain game online dibandingkan melakukan aktivitas lain. hal tersebut yang menjadikan mereka lebih rentan mengalami kecanduan dalam bermain game online.

Pada tabel 3 juga memperlihatkan ditemukan sebanyak $19(27,9 \%)$ responden mengalami kecanduan game online terkontrol. Peneliti berasumsi bahwa remaja yang mengalami kencanduan game online terkontrol dikarenakan mereka memiliki kontrol diri yang baik, hal itu dapat dilihat dari tidak adanya masalah dalam kriteria-kriteria kecanduan game online. Hal tersebut sesuai dengan pernyataan Budhi \& Indrawati (2016), dimana semakin tinggi kontrol diri yang dimiliki seorang remaja, maka semakin rendah peluang seorang remaja mengalami kecanduan game online.

Hasil penelitian juga memperlihatkan bahwa tingkat kecanduan game online yang 
terjadi pada remaja di SMA N 1 Tondano sangat tinggi. Penelitian yang dilakukan oleh Jap, Tiatri, Jaya, \& Suteja (2013), mengungkapkan bahwa $10,15 \%$ atau 1 dari 10 remaja di Indonesia terindikasi mengalami kecanduan game online. Fenomena kecanduan game online semakin memprihatinkan dimana orang yang sering mengalami kecanduan game online adalah para generasi muda atau mereka yang berusia remaja.

Kuesioner kecanduan game online yang dibagikan pada responden terdiri dari pertanyaan-pertanyaan untuk melihat kriteria dalam kecanduan game online, yaitu salience atau bermain game online menjadi aktivitas paling penting dalam kehidupan mereka (didominasi oleh pikiran keasyikan, rasa ketagihan, serta perilaku penggunaan berlebihan), tolerance atau waktu yang digunakan dalam bermain game online semakin bertambah dan tidak dapat berhenti ketika sedang bermain, mood modification atau bermain game online dengan tujuan mengubah perasaan, relapse atau kesulitan mengurangi waktu bermain game online, withdrawal atau merasa tidak enak ketika tidak dapat bermain, conflict atau bertengkar dengan orang lain karena bermain game online, dan problems atau bermain game online menyebabkan timbulnya masalah dalam dirinya sendiri (Lemmens, 2009). Berdasarkan analisa kuesioner yang dilakukan oleh peneliti, responden yang mengalami kecanduan game online tidak terkontrol mengalami masalah pada kriteria salience hal tersebut ditandai dengan perilaku penggunaan yang berlebihan dimana pemain selalu memikirkan dan menggunakan waktu luangnya untuk bermain game online sepanjang waktu, tolerance yang ditandai dengan waktu yang digunakan dalam bermain game online semakin bertambah, mood modification yang ditandai dengan bermain game online untuk mencari kesenangan dan menghilangkan stres, relapse yang ditandai dengan kesulitan untuk mengurangi waktu dalam bermain game online, dan problem yang ditandai dengan pemain yang bermain game online menyebabkan gangguan dalam proses istirahat. Sedangkan responden yang mengalami kecanduan game online terkontrol tidak mengalami masalah dalam berbagai kriteria. Menurut Puspita \& Mulyana (2018), salah satu faktor penyebab seorang remaja mengalami kecanduan game online adalah lack of control atau ketidakmampuan remaja dalam mengontrol diri mereka dalam bermain game online.

Berdasarkan hasil tersebut, insomnia yang dialami oleh siswa dan siswi di SMA N 1 Tondano berada pada tingkat insomnia ringan walaupun sebagiannya mengalami insomnia berat. Berdasarkan analisa kuesioner yang dilakukan oleh peneliti, remaja yang mengalami insomnia ringan memiliki tanda dan gejala insomnia yang hanya berlangsung singkat, hal tersebut dilihat dari pilihan jawaban responden dalam kuesioner dimana responden kadang mengalami kesulitan untuk memulai tidur, tiba-tiba terbangun pada malam hari, rasa mengantuk di siang hari, sakit kepala di siang hari, kurang puas dengan tidur, kurang nyaman/gelisah saat tidur, badan terasa lemah, letih dan kurang tenaga. Sedangkan responden yang mengalami insomnia berat semuanya memilih jawaban selalu pada beberapa pilihan jawaban dalam kuesioner dimana, responden selalu mengalami kesulitan untuk memulai tidur, tiba-tiba terbangun pada malam hari, rasa mengantuk disiang hari, sakit kepala disiang hari, kurang puas dengan tidur, kurang nyaman/gelisah saat tidur, badan terasa lemah, letih dan kurang tenaga.

Hal ini didukung oleh penelitian yang dilakukan oleh Luas, Maramis, dan Wowor (2019) di SMA Advent Tanah Putih Likupang Barat, dimana dari 136 remaja, terdapat $107(78 \%)$ remaja yang mengalami insomnia dan $29(21,3 \%)$ remaja tidak mengalami insomnia, artinya remaja merupakan salah satu populasi yang sering mengalami insomnia selain orang dewasa maupun lansia. Berdasarkan hal tersebut, insomnia tidak hanya dialami oleh orang 
dewasa tetapi yang paling sering mengalami insomnia adalah remaja. Menurut Saputra (2013), salah satu penyebab remaja mengalami insomnia adalah faktor gaya hidup, sebagai contohnya adalah penggunaan internet yang secara berlebihan. Hal tersebut didukung oleh Owens (2014), dimana faktor penyebab remaja mengalami insomnia adalah karena pola tidur yang buruk karena aktifitas penggunaan media elektronik (televisi, computer, gadget dan lain sebagainya) yang secara berlebihan. Hal tersebut juga didukung oleh penelitian yang dilakukan oleh Mawitjere (2017), didapatkan bahwa dari 39 responden yang menggunakan gadget, terdapat 29 responden yang mengalami insomnia ringan

Hasil penelitian menggunakan uji korelasi Spearman dengan tingkat kepercayaan $95 \%$ didapatkan nilai $r=0,003<\alpha=0,05$. Hasil tersebut menunjukan bahwa hipotesis peneliti diterima yang artinya, ada hubungan yang signifikan antara kecanduan game online dengan insomnia pada remaja di SMA N 1 Tondano. Dari hasil penelitian tersebut responden yang mengalami kecanduan game online terkontrol disertai insomnia ringan sebanyak 19 responden (100\%) dan tidak ada yang mengalami insomnia berat. Berdasarkan analisa kuesioner yang dilakukan oleh peneliti, responden yang mengalami kecanduan game online terkontrol cenderung memiliki tanda dan gejala insomnia yang singkat, artinya tanda dan gejala insomnia yang mereka alami tidak terjadi secara rutin.

Hasil penelitian tersebut juga menunjukan bahwa terdapat 32 responden $(65,3 \%)$ mengalami kecanduan game online tidak terkontrol disertai dengan insomnia ringan. Melalui analisa kuesioner yang dilakukan peneliti, dari 7 kriteria kecanduan game online responden yang mengalami kecanduan game online tidak terkontrol yang disertai insomnia ringan sebagian besar hanya memiliki masalah dari 2 kriteria, yaitu Salience dan Mood modification, artinya game online yang dimainkan oleh responden telah mendominasi pikiran sehingga responden menjadi keasyikan dalam bermain, serta menganggap bahwa bermain game online memberikan mereka perasaan senang. Responden yang mengalami masalah dalam 2 kriteria kecanduan game online tersebut, mengalami tanda dan gejala insomnia yang singkat, hal tersebut dilihat dari pilihan jawaban responden yang hanya memilih pilihan jawaban kadang-kadang dan sering. Sedangkan untuk responden yang mengalami kecanduan game online tidak terkontrol yang disertai insomnia berat terdapat 17 responden $(34,7 \%)$, dari hasil analisa kuesioner yang dilakukan peneliti, responden tersebut mengalami masalah dalam 5 kriteria kecanduan game online, yaitu salience, tolerance, mood modification, relapse, dan problems. Reponden yang mengalami 5 kriteria tersebut mengalami tanda dan gejala insomnia secara rutin.

Remaja yang mengalami kecanduan game online tidak luput dari penggunaan gadget khususnya untuk hiburan. Penelitian yang dilakukan oleh Mawitjere (2017) tentang hubungan penggunaan gadget dengan insomnia pada remaja, didapatkan bahwa terdapat hubungan yang signifikan antara penggunaan gadget dengan kejadian insomnia pada remaja. Ada juga penelitian yang dilakukan oleh Nurdilla (2018), didapatkan bahwa kecanduan game online dapat berpengaruh terhadap kualitas tidur, dimana remaja yang kecanduan game online cenderung akan terus menambah waktunya dalam bermain sehingga mereka lupa untuk beristirahat. Hal tersebut didukung oleh Astuti dan Burhanto (2018), dimana semakin tinggi kecanduan seseorang dalam bermain game online maka semakin buruk kualitas tidur yang dialami oleh pemain game online. penelitian tersebut memiliki persamaan dengan penelitian ini yaitu sama-sama meneliti kecanduan game online yang berhubungan dengan istirahat dan tidur, 
hanya saja penelitian tersebut hanya membahas kualitas tidurnya saja dan tidak membahas masalah atau gangguan tidur yang diakibatkan oleh kecanduan game online.

Kecanduan game online sangat erat kaitannya dengan gangguan/masalah tidur. Salah satu faktor penyebab terjadinya insomnia adalah gaya hidup monoton, dimana seseorang akan lebih mementingkan bermain dari pada memenuhi kebutuhan istirahat dan tidurnya (Young, 2009). Hal tersebut dialami oleh remaja di SMA N 1 Tondano, dimana mereka yang mengalami kecanduan game online tidak terkontrol menyebabkan mereka kesulitan berhenti dalam bermain yang pada akhirnya mereka mengalami kesulitan untuk memulai tidur maupun gangguan saat sedang tidur sehingga mereka mengalami insomnia.

Berdasarkan hasil penelitian yang didapatkan pada remaja di SMA N 1 Tondano serta beberapa penelitian pendukung yang sudah disebutkan diatas, dapat disimpulkan bahwa kecanduan game online sangat berhubungan erat dengan masalah terjadinya insomnia. Hal tersebut dilihat dari perilaku penggunaan game online yang secara berlebihan sehingga menyebabkan seseorang mengalami insomnia khususnya remaja, dimana semakin terkontrol kecanduan game online yang dialami maka semakin rendah tingkat insomnia yang dialami oleh remaja, begitu pula sebaliknya semakin tidak terkontrol kecanduan game online yang dialami maka semakin tinggi tingkat insomnia yang dialami oleh remaja.

\section{KESIMPULAN}

Penelitian ini menyimpulkan Sebagian besar responden remaja di SMA N 1 Tondano mengalami kecanduan game online tidak terkontrol dan diikuti dengan insomnia ringan.

\section{DAFTAR PUSTAKA}

Asosiasi Penyelenggara Jasa Internet Indonesia. (2018). Penetrasi \& profil perilaku pengguna internet Indonesia survei 2018. https://apjii.or.id/survei2018/down load/94IpUV5Kjaqnt3GdHWFw MvOE6hZiuJ. Diakses pada 18 februari 2020.

Astuti \& Burhanto. (2018). Hubungan Kecanduan Bermain Game Online Dengan Kualitas Tidur Siswa/Siswi Di SMP Negeri 24 Samarinda.

https://dspace.umkt.ac.id/bitstrea $\mathrm{m} /$ handle/463.2017/935/SKR\%20 SRI\%20ASTUTI.pdf?sequence $=1$ \&isAllowed $=\mathrm{y}$. Diakses pada 21 Februari 2020.

Budhi \& Indrawati. (2016). Hubungan Antara Kontrol Diri Dengan Intensitas Bermain Game online Pada Mahasiswa Pemain Game Online Di Game Center X Semarang. https://media.neliti.com/media/pu blications/63402-ID-hubunganantara-kontrol-diri-denganinte.pdf . Diakses pada 05 Juni 2020.

Fransisca. (2015). Perbedaan Tingkat Kecanduan Game Online Pada Remaja Antar Gaya Pengasuhan. https://repository.usd.ac.id/10231/ 2/109114133 full.pdf. Diakses pada 21 Februari 2020

Gentille, Lynder, Walsh. (2004). The effects of violent video game habits on adolescent hostility, aggressive behaviors, and school performance. Journal of adolescence. doi:10.1016/j.adolescence. 2003.10 .002. Diakses pada 18 februari 2020. 
Jap, T., Tiatri, S., Jaya, E. S., \& Suteja, M. S. (2013). The Development of Indonesian Online Game Addiction Questionnaire. PLoS ONE, $\quad$ 8(4), e61098. doi:10.1371/journal.pone.0061098 . diakses pada 4 mei 2020

Jiang, Q. (2014). Internet addiction among young people in China. Internet Research, 24(1), 2-20. doi:10.1108/intr-01-2013-0004. Diakses pada 4 mei 2020.

Koo, Wati, Choong, Hea. (2011). InternetAddicted Kids and South Korean Government Efforts: Boot-camp Case. Journal of cyberpsychology, behavior, and social networking. doi:10.1089/cyber.2009.0331. diakses pada 18 februari 2020 .

Kuss, D. J., \& Griffiths, M. D. (2011). Internet Gaming Addiction: A Systematic Review of Empirical Research. International Journal of Mental Health and Addiction, 10(2), 278-296. doi:10.1007/s11469-011-9318-5. Diakses pada 4 mei 2020.

Lam, L. T. (2014). Internet Gaming Addiction, Problematic Use of the Internet, and Sleep Problems: A Systematic Review. Current Psychiatry Reports, 16(4). doi:10.1007/s11920-014-0444-1. Diakses pada 18 februari 2020.

Luas, Maramis, \& Wowor. (2019). Hubungan Antara Penggunaan Media Sosial Dengan Kejadian Insomnia Pada Remaja Di SMA Advent Tanah Putih Likupang Barat. Jurnal KESMAS. https://ejournal.unsrat.ac.id/index. php/kesmas/article/download/240 $\underline{12 / 23697}$. Diakses pada 4 mei 2020

Mawitjere, Onibala, \& Ismanto. (2017). Hubungan Lama Penggunaan Gadget Dengan Kejadian
Insomnia Pada Siswa Siswi Di SMA Negeri 1 Kawangkoan. EJurnal Unsrat. https://ejournal.unsrat.ac.id/index. php/jkp/article/download/15827/1 5336. Diakses pada 4 Mei 2020.

Newzoo. (2018). Global Game Market Report.

https://newzoo.com/global-gamesmarket-report . Diakses pada 18 februari 2020.

Notoatmodjo. (2012). Metodologi Penelitian Kesehatan. Jakarta: Rineke Cipta

Nurdilla, N. (2018). Hubungan Kecanduan Game Online Dengan Kualitas Tidur Remaja. https://jom.unri.ac.id/index.php/J OMPSIK/article/view/21007 Diakses pada 18 februari 2020.

Owens, J. (2014). Insufficient Sleep in Adolescents and Young Adults:An Update on Causes and Consequences. American academy of pediatric. Doi: doi:10.1542/peds.2014-1696. Diakses pada 18 februari 2020.

Puspita \& Mulyana. (2018). Hubungan Antara Kontrol Diri Dengan Kecanduan Game Online Pada Remaja Akhir. Jurnal Penelitian Psikologi. Diakses pada 4 Mei 2020.

Rondo, Wungou, \& Onibala. (2019). Hubungan Kecanduan Game online dengan perilaku agresif siswa di SMA N 2 Ratahan. EJurnal Unsrat. https://ejournal.unsrat.ac.id/index. php/jkp/article/view/24324/23992 . Diakses pada 18 februari 2020.

Saputra, L. (2013). Pengantar Kebutuhan Dasar Manusia. Tanggerang Selatan: Binarupa Aksara. 
World Health Organization. (2018). Inclusion of "gaming disorder" in ICD-11. https://www.who.int . Diakses pada 18 Februari 2020.

Young, K. (2009). Understanding Online Gaming Addiction and Treatment
Issues for Adolescents. The American Journal of Family Therapy, 37(5), 355-372. doi:10.1080/01926180902942191. Diakses pada 18 Februari 2020. 